\title{
Oxygen Sensor Device
}

National Cancer Institute

\section{Source}

National Cancer Institute. Oxygen Sensor Device. NCI Thesaurus. Code C50168.

A sensor designed to respond to the presence or level of oxygen in a space or environment. 